\title{
Cultural Adaptation and Psychometric properties of Brazilian and Peruvian versions of the Behavioral Activation for Depression Scale Short Form (BADS- SF)
}

\section{Suzana Crismanis Almeida Lopes Aschar ( $\nabla$ suzana.aschar@usp.br)} Universidade de São Paulo

Heloísa Garcia Claro

State University of Campinas

Ivan Filipe de Almeida Lopes Fernandes

Universidade Federal do ABC

Kate Daley

Universidade de São Paulo

Hellen Carolina Martins Castro

Universidade de São Paulo

Daniela Vera Cruz dos Santos

Universidade de São Paulo

Thais Izabel Ugeda Rocha

Universidade de São Paulo

Ines Hungerbuehler

TNH Health

Ricardo Araya

King's College London

\section{Paulo Rossi Menezes}

Universidade de São Paulo

\section{Research Article}

Keywords: Mental Health, Depression, Behavior Activation, Validation Studies.

Posted Date: February 26th, 2021

DOl: https://doi.org/10.21203/rs.3.rs-243905/v1

License: (c) (1) This work is licensed under a Creative Commons Attribution 4.0 International License. 
Page $2 / 19$ 


\section{Abstract}

Background: Behavioral Activation (BA) is an evidence-based treatment that aims to help the individual to stay active and reduce avoidance behaviors, as a means to reduce depressive symptoms. This study aims to describe the adaptation process and evaluate the psychometric properties of the Behavioral Activation for Depression Scale Short Form (BADS-SF) in its Brazilian and Peruvian version.

Methods: Data were collected as part of a randomized trial with 880 participants in Brazil and 432 in Peru. The content validity was assessed using the Content Validity Index (CVI). Principal Component Analysis (PCA) method was applied to evaluate the factorial distribution. Sampling adequacy was assessed by Bartlett's test of Sphericity and Kaiser-Meyer-Olkin measure. Cronbach's alpha coefficient was calculated to assess internal consistency.

Results: CVI in Brazil was 0.92 and in Peru 0.87. The two-factor solution of the original scale is sustained (activation and avoidance), accounting for 50.6 and $54 \%$ of the total variance in Brazil and Peru, respectively. Cronbach's alpha in Brazil was 0.55 and 0.66 in Peru for the overall scale. KMO was 0.769 and 0.790 for Brazil and Peru, respectively. Bartlett's test of Sphericity had significance of 0.000 for both samples.

Conclusion: Both studied versions of the BAD-SF showed coherent structure and internal consistency. We recommend different distribution of the items into the subscales.

\section{Background}

Validated instruments provide valuable information for treatment, contributing to the management of clinical practice. The use of the same tool in different cultures enables international comparative studies, providing epidemiological information that can support interventions and public policies [1]. The adaptation of instruments in multiple cultures also allows greater generalization and identification of differences in increasingly diverse and mixed cultures [2].

Major Depressive Disorder (MDD) is one of the most prevalent psychiatric disorders in the world, affecting more than 264 million people worldwide [3]. It represents $4.3 \%$ of the global disease burden (GBD) [4] and it is expected to be the largest representative of this index by 2030 [5]. Depression can be long lasting and severe, impacting all areas of an individual's life, being listed among the main causes of disability, corresponding to $11 \%$ of the years lived with disability (YLDs) [4].

MDD is the main risk factor associated with suicide [6], causing approximately 800 thousand deaths per year, the third leading cause of death among young people [7]. In Brazil, depressive disorders affect almost $6 \%$ of the population and correspond to $10.3 \%$ YLDs. In Peru, depressive disorders are equally prevalent : almost $5 \%$ of the population is affected by depression, representing $9.7 \%$ YLDs [8]. 
Depression is associated with poverty, low education, and social exclusion, significant factors in lowmiddle income countries (LMICs) [8], such as Brazil and Peru. These countries also face major challenges regarding access to treatment, particularly specific groups such as indigenous, low income, and vulnerable populations meaning $80 \%$ of people cannot access any mental health treatment. The treatment gap exacerbates mental health burden and social impact [9].

Behavioral Activation (BA) is an evidence-based treatment for depression that seeks to increase opportunities for the depressed individual to get in contact with reinforcement contingencies that oppose the situation of confinement and reduction of social activities/contacts that contribute to the establishment and worsening of depression [10]. BA is often referred to as an effective and easy to disseminate treatment and holds promise to be highly adaptable for different settings and cultures, standing as a useful approach to address the gap in mental health care in LMICs $[11,12]$.

To evaluate the effectiveness of BA several measures were used, but none of the preexistent scales focused on behavior functions and its idiographic nature [13]. The Behavioral Activation for Depression Scale Short Form (BADS-SF) comprises nine items distributed in two subscales, activation, and avoidance, both pillars of the treatment rationale [14]. The BADS-SF has been successfully adapted and validated in French, German, and Japanese.

This study aimed to adapt and evaluate the psychometric properties of the BADS-SF in its Brazilian and Peruvian versions.

\section{Methods}

The Brazilian and Peruvian versions of the BADS-SF were administered to participants as part of a randomized clinical trial (RCT) which evaluated the effectiveness of a BA intervention in the treatment of depressive symptoms through a mobile application. The study was developed and carried out by the LATIN-MH research hub (Latin America Treatment and Innovation Network), based at the city of São Paulo, Brazil, in the Medicine School of University of São Paulo (FMUSP) and Peruvian University Cayetano Heredia, in Lima, Peru. It was conducted between the years 2016 and 2018 with funding provided by the National Institutes of Health $(\mathrm{NIH})$.

Ethics approvals were obtained in both universities' review boards and all required government agencies. This included all health services ethics boards in Peru.

RCT Project registration number in Brazil 2.636.669 and CAAEE: 54416516.7.0000.0065, which derived the present study under registration number 3.761.649 and CAAEE 26392719.6.0000.0065. [Trial registration NCT028406662 (Brazil), NCT03026426 (Peru)].

The author of the original version of the BADS-SF permitted its translation and adaptation for Brazilian Portuguese and Peruvian Spanish. 
Participants in Brazil $(n=880)$ were recruited from 20 Family Health Units $(F H U)$, cluster-randomized into 10 intervention-units and 10 control-units with equal number of participants per unit $(n=44)$.

In Peru, participants $(n=432)$ were recruited from three tertiary hospitals and four Primary Health Care Centers for the elderly $(\mathrm{PHC})$ and individually randomized into a control group $(n=215)$ and an intervention group $(n=217)$.

All participants had diabetes and/or hypertension, were 21 years or older, literate, and had a score of 10 or more on the Patient Health Questionnaire 9 (PHQ-9).

Those who showed medium-high or high suicidal ideation in the PHQ-9 assessment were excluded from the study [15].

The process of cross-cultural adaptation of the original scale to Brazilian Portuguese was based on the procedures outlined by Beaton et. al. [16]. Two translators affiliated to the RCT, one psychologist and one nurse, both fluent in English, created two independent versions of the scale. Both versions were discussed by the translators and after resolving differences and ambiguities, were synthesized in a 3rd version. This version was back-translated into English by a third translator, native in English and fluent in Portuguese, not related to the study, to verify the translation accuracy. Finally, a committee composed of five health experts, Brazilian and fluent in English, were requested to, individually, compare the adapted version of the scale to the original one, make suggestions and comment on its appropriateness, and compute two separate grades in a Likert scale ranging from 1 to 5 ( 1 - very bad; 2 - bad; 3 - regular; 4 - good and 5 - very good), concerning its idiomatic and conceptual equivalence [17].

Regarding the Peruvian process, As the BAD-SF is composed of 7 items taken from the BADS and one additional item [18], translation was needed for this additional item. The other items underwent idiomatic adaptations to expressions used with the Peruvian vocabulary. Two psychologists conducted this process, and the result was submitted to six judges, experts in mental health, for the same idiomatic and conceptual equivalence analysis that occurred in the Brazilian adaptation.

\section{Statistical Analysis}

\section{Assessment of the Content Validity}

After the process of cross-cultural adaptation, the content validity of both versions of the BADS-SF was measured using the Content Validity Index (CVI) calculation. This index measures the judges' level of agreement on how similar the adapted version is regarding comprehensiveness and representativeness when compared to the original version $[19,20]$.

First, the proportion of 4 (good) or 5 (very good) in each item was calculated for both categories, idiomatic and conceptual equivalence, a total of 18 grades per expert. After that, the CVI was calculated by the mean of this proportion. The CVls were considered acceptable if the values are superior to 0.80 [21].

\section{Assessment of the construct validity}


The construct validity of the scale was assessed by the Principal Component Analysis (PCA) method. This analysis allows us to confirm the factor analysis of the original scale or to propose a new model of factors for the Brazilian and Peruvian contexts. The Promax method was used for factor rotation.

Bartlett's test of Sphericity and KMO (Kaiser-Meyer-Olkin) measure was extracted to confirm sampling adequacy.

\section{Reliability assessment (Cronbach's alpha)}

Cronbach's alpha coefficient was calculated to assess the internal consistency of the items for each version of the scale. Values from 0.60 were considered acceptable, as observed in the literature [22].

\section{Quality supervision of the study}

To ensure the quality of the study and data collection, the BADS-SF completion was facilitated by trained researchers. Participants completed the BAD-SF at the time of inclusion, after 3 months (1st follow-up assessment), and again at 6 months (2nd follow-up assessment).

The data were electronically collected and protected by encryption. Missing data were excluded using the pairwise deletion analysis approach [23].

Statistical analyses were performed using Stata, version 15 (StataCorp LLC, TX, USA) and SPSS Statistics version 20 (IBM, NY, USA) software.

\section{Results}

This study had 880 participants in Brazil and 432 in Peru. In both localities, participants were mainly female ( $86 \%$ in Brazil and $81 \%$ in Peru), aged between 41 and 60 years old (53\% and $45 \%$, respectively). Regarding depressive symptoms, $42 \%$ of Brazilian and $63 \%$ of Peruvian participants were classified as having moderate symptoms.

The majority did not present suicide risk $(68 \%$ and $56 \%)$ and were not receiving treatment for depressive symptoms at the time of the baseline assessment (83\% and $91 \%)$. Table 1 presents other baseline characteristics of the participants. 
Table 1

Baseline characteristics of the participants of BADS-SF adaptation and psychometric properties assessment

\begin{tabular}{|c|c|c|c|}
\hline & & $\begin{array}{l}\text { Brazil }(n= \\
880)\end{array}$ & $\begin{array}{l}\text { Peru }(n= \\
432)\end{array}$ \\
\hline & & \multicolumn{2}{|c|}{ Frequency (percentage) } \\
\hline \multirow[t]{2}{*}{ Gender } & Female & $761(86.5)$ & $352(81.5)$ \\
\hline & Male & $119(13.5)$ & $80(18.5)$ \\
\hline \multirow[t]{3}{*}{ Diagnosis } & Hypertension & $471(53.5)$ & $121(28.0)$ \\
\hline & Diabetes & $90(10.2)$ & $185(42.8)$ \\
\hline & Hypertension + Diabetes & $319(36.3)$ & $126(29.2)$ \\
\hline \multirow[t]{3}{*}{ Age } & 21 a 40 & $89(10.1)$ & $21(4.8)$ \\
\hline & 41 a 60 & $468(53.2)$ & $196(45.4)$ \\
\hline & $>=61$ & $323(36.7)$ & $215(49.8)$ \\
\hline \multirow[t]{4}{*}{ Job } & Employed & $66(7.5)$ & $25(5.8)$ \\
\hline & Self-employed & $126(14.3)$ & $129(29.8)$ \\
\hline & Unemployed/ Housewife & $442(50.2)$ & $250(57.9)$ \\
\hline & Other & $246(28.0)$ & $28(6.5)$ \\
\hline \multirow[t]{7}{*}{ Education Level } & Incomplete primary school & $443(50.3)$ & 72 (16.7) \\
\hline & Complete primary school & $172(19.5)$ & $112(25.9)$ \\
\hline & Complete high school & $180(20.5)$ & $114(26.4)$ \\
\hline & Complete technical school & $12(1.4)$ & $83(19.2)$ \\
\hline & Started or completed university & $62(7.0)$ & $51(11.8)$ \\
\hline & Started or completed post-graduate & $10(1.1)$ & 0 \\
\hline & Did not answer & $1(0.1)$ & 0 \\
\hline \multirow[t]{4}{*}{ Income ${ }^{1}$} & up to 2 local minimum wage & $599(68.0)$ & $200(69.4)$ \\
\hline & 2 to 4 local minimum wages & $217(24.7)$ & $85(19.7)$ \\
\hline & $>4$ local minimum wages & $54(6.1)$ & $35(8.1)$ \\
\hline & Did not know/refused to answer & $10(1.1)$ & $12(2.8)$ \\
\hline \multirow[t]{2}{*}{ Marital Status } & Married & $508(57.7)$ & $238(55.1)$ \\
\hline & Single & $111(12.6)$ & $62(14.4)$ \\
\hline
\end{tabular}




\begin{tabular}{|c|c|c|c|}
\hline & & $\begin{array}{l}\text { Brazil }(n= \\
880)\end{array}$ & $\begin{array}{l}\text { Peru }(n= \\
432)\end{array}$ \\
\hline & Divorced/ Widow/ other & $161(29.7)$ & $132(30.5)$ \\
\hline \multirow{3}{*}{$\begin{array}{l}\text { Depressive } \\
\text { Symptoms }\end{array}$} & Moderate & $373(42.4)$ & $275(63.6)$ \\
\hline & Moderately severe & $315(35.8)$ & $113(26.2)$ \\
\hline & Severe & $192(21.8)$ & $44(10.2)$ \\
\hline \multirow[t]{5}{*}{ Suicide Risk } & Never considered suicide & $208(23.6)$ & $157(36.3)$ \\
\hline & $\begin{array}{l}\text { Considered suicide within the last } 2 \\
\text { weeks }\end{array}$ & $56(6.4)$ & $20(4.6)$ \\
\hline & Suicide plans & $7(0.8)$ & $5(1.2)$ \\
\hline & Suicide plans and means & $9(1.0)$ & $6(1.4)$ \\
\hline & No risk ${ }^{2}$ & $600(68.2)$ & $244(56.5)$ \\
\hline \multirow[t]{4}{*}{ BADS-SF Score } & Up to 21 & $428(48.6)$ & $146(33.8)$ \\
\hline & $22-28$ & $232(26.4)$ & $146(33.8)$ \\
\hline & Above 28 & 217 (24.7) & $139(3.2)$ \\
\hline & Missing data ${ }^{3}$ & $3(0.3)$ & $1(0.2)$ \\
\hline \multicolumn{4}{|c|}{${ }^{1}$ minimum wage: Brazil = 880 Reais; Peru $=750$ Soles } \\
\hline \multicolumn{4}{|c|}{$\begin{array}{l}2 \text { Participants in the "no risk" category are those who did not originated a questionnaire about suicida } \\
\text { ideation. }\end{array}$} \\
\hline \multicolumn{4}{|c|}{$\begin{array}{l}{ }^{3} \text { Missing data represents responses not included in analysis due to the lack of essential information } \\
\text { in the system. }\end{array}$} \\
\hline
\end{tabular}

The Content Validity Index in Brazil was 0.91 and in Peru 0.86 , both considered acceptable. The CVI for the whole scale and items are presented in Table 2. 
Table 2

Content validity of the Brazilian and Peruvian versions of the Behavioral Activation for Depression Scale Short Form

\section{Content Validity Index}

\begin{tabular}{|c|c|c|c|c|}
\hline & Brazil & & Peru & \\
\hline Complete scale CVI & 0.92 & & 0.87 & \\
\hline Item & $\begin{array}{l}\text { Conceptual } \\
\text { Equivalence }\end{array}$ & $\begin{array}{l}\text { Idiomatic } \\
\text { Equivalence }\end{array}$ & $\begin{array}{l}\text { Conceptual } \\
\text { Equivalence }\end{array}$ & $\begin{array}{l}\text { Idiomatic } \\
\text { Equivalence }\end{array}$ \\
\hline $\begin{array}{l}\text { 1. There were certain things I needed to } \\
\text { do that I didn't do. }\end{array}$ & 0.960 & 1.000 & 0.867 & 0.900 \\
\hline $\begin{array}{l}\text { 2. I am content with the amount and } \\
\text { types of things I did. }\end{array}$ & 0.960 & 0.960 & 0.800 & 0.767 \\
\hline $\begin{array}{l}\text { 3. I engaged in many different } \\
\text { activities. }\end{array}$ & 1.000 & 1.000 & 0.767 & 0.833 \\
\hline $\begin{array}{l}\text { 4. I made good decisions about what } \\
\text { type of activities and/or situations I put } \\
\text { myself in. }\end{array}$ & 0.840 & 0.800 & 0.867 & 0.867 \\
\hline $\begin{array}{l}\text { 5. I was an active person and } \\
\text { accomplished the goals I set out to do. }\end{array}$ & 0.800 & 0.760 & 0.867 & 0.900 \\
\hline $\begin{array}{l}\text { 6. Most of what I did was to escape } \\
\text { from or avoid something unpleasant. }\end{array}$ & 1.000 & 1.000 & 0.900 & 0.900 \\
\hline $\begin{array}{l}\text { 7. I spent a long time thinking over and } \\
\text { over about my problems. }\end{array}$ & 1.000 & 1.000 & 0.833 & 0.833 \\
\hline $\begin{array}{l}\text { 8. I engaged in activities that would } \\
\text { distract me from feeling bad. }\end{array}$ & 0.800 & 0.840 & 0.867 & 0.833 \\
\hline 9. I did things that were enjoyable. & 0.800 & 0.840 & 0.933 & 0.933 \\
\hline $\begin{array}{l}\text { Mean of the measures within } \\
\text { categories for the complete scale }\end{array}$ & 0.907 & 0.911 & 0.856 & 0.863 \\
\hline
\end{tabular}

Table 3 shows the communalities of the BADS-SF items for both adapted versions. Item 3 (I engaged in many different activities) of the Brazilian version is the only item presenting a communality value lower than 0.4 . 
Table 3

Items communalities of the Brazilian and Peruvian versions of the Behavioral Activation for Depression Scale - Short Form

\begin{tabular}{|lll|}
\hline & \multicolumn{2}{l|}{ Communality } \\
\hline Item & $\begin{array}{l}\text { Brazilian } \\
\text { version }\end{array}$ & $\begin{array}{c}\text { Peruvian } \\
\text { version }\end{array}$ \\
\hline 1. There were certain things I needed to do that I didn't do. & 0.493 & 0.412 \\
\hline 2. I am content with the amount and types of things I did. & 0.499 & 0.505 \\
\hline 3. I engaged in many different activities. & 0.308 & 0.466 \\
\hline $\begin{array}{l}\text { 4. I made good decisions about what type of activities and/or } \\
\text { situations I put myself in. }\end{array}$ & 0.623 & 0.557 \\
\hline $\begin{array}{l}\text { 5. I was an active person and accomplished the goals I set out to do. } \\
\text { 6. Most of what I did was to escape from or avoid something }\end{array}$ & 0.620 & 0.619 \\
\hline $\begin{array}{l}\text { unpleasant. } \\
\text { 7. I spent a long time thinking over and over about my problems. }\end{array}$ & 0.499 & 0.629 \\
\hline 8. I engaged in activities that would distract me from feeling bad. & 0.506 & 0.630 \\
\hline 9. I did things that were enjoyable. & 0.497 & 0.549 \\
\hline
\end{tabular}

The results of the factorial analysis calculated by PCA confirmed the existence of two primary factors for the BADS-SF in Brazil and Peru. In Table 4 we present initial and rotated eigenvalues for both versions of the BADS-SF. The naming of each factor followed the names for the original version of the scale.

Table 4

Initial and rotated eigenvalues of 2-factor of the Brazilian and Peruvian versions of the Behavioral Activation for Depression Scale - Short Form

\begin{tabular}{|lccccccc|}
\hline & \multicolumn{3}{c}{ Initial Eigenvalue } & \multicolumn{5}{c|}{ Promax rotation } \\
\hline & Factor & Total & $\begin{array}{l}\text { Variance } \\
\%\end{array}$ & $\begin{array}{l}\text { Cumulative } \\
\%\end{array}$ & Total & $\begin{array}{l}\text { Variance } \\
\%\end{array}$ & $\begin{array}{l}\text { Cumulative } \\
\%\end{array}$ \\
\hline $\begin{array}{l}\text { Brazilian } \\
\text { version }\end{array}$ & 1 & 2.72 & 30.18 & 30.18 & 2.69 & 29.97 & 29.97 \\
\hline & 2 & 1.86 & 20.62 & 50.8 & 1.88 & 20.95 & 50.92 \\
\hline $\begin{array}{l}\text { Peruvian } \\
\text { version }\end{array}$ & 1 & 2.92 & 32.49 & 32.49 & 2.90 & 32.24 & 32.24 \\
\hline & 2 & 2.02 & 22.44 & 54.93 & 2.06 & 22.87 & 55.11 \\
\hline
\end{tabular}


The first factor, named "Activation", explained $30 \%$ of the variance of the Brazilian version and $32 \%$ of the Peruvian version. The second factor, "Avoidance", explained $20.6 \%$ of the variance in Brazil and $22 \%$ in Peru. Factor load scree plots are shown in Fig. 1 and Fig. 2.

The factor load of the items indicating their distribution around the extracted factors is demonstrated in Table 5. All items were higher than the adopted cutoff point of 0.4 [24].

Table 5

Factor load of items of the Brazilian and Peruvian version of Behavioral Activation for Depression Scale Short form

\begin{tabular}{|c|c|c|c|c|}
\hline \multirow[b]{3}{*}{ Item } & \multicolumn{2}{|c|}{ Brazilian Version } & \multicolumn{2}{|c|}{ Peruvian Version } \\
\hline & \multicolumn{4}{|c|}{ Factor Load } \\
\hline & $\begin{array}{l}1- \\
\text { Activation }\end{array}$ & $\begin{array}{l}\text { 2- } \\
\text { Avoidance }\end{array}$ & $\begin{array}{l}1- \\
\text { Activation }\end{array}$ & $\begin{array}{l}\text { 2- } \\
\text { Avoidance }\end{array}$ \\
\hline $\begin{array}{l}\text { 1. There were certain things I needed to do that } \\
\text { I didn't do. }\end{array}$ & 0.266 & 0.661 & 0.249 & 0.579 \\
\hline $\begin{array}{l}\text { 2. I am content with the amount and types of } \\
\text { things I did. }\end{array}$ & 0.690 & 0.182 & 0.675 & 0.193 \\
\hline 3. I engaged in many different activities. & 0.515 & -0.189 & 0.666 & -0.186 \\
\hline $\begin{array}{l}\text { 4. I made good decisions about what type of } \\
\text { activities and/or situations I put myself in. }\end{array}$ & 0.786 & 0.106 & 0.747 & -0.054 \\
\hline $\begin{array}{l}\text { 5. I was an active person and accomplished } \\
\text { the goals I set out to do. }\end{array}$ & 0.777 & -0.103 & 0.761 & 0.168 \\
\hline $\begin{array}{l}\text { 6. Most of what I did was to escape from or } \\
\text { avoid something unpleasant. }\end{array}$ & -0.142 & 0.686 & -0.102 & 0.792 \\
\hline $\begin{array}{l}\text { 7. I spent a long time thinking over and over } \\
\text { about my problems. }\end{array}$ & 0.092 & 0.724 & 0.198 & 0.759 \\
\hline $\begin{array}{l}\text { 8. I engaged in activities that would distract } \\
\text { me from feeling bad. }\end{array}$ & -0.365 & 0.596 & -0.447 & 0.637 \\
\hline 9. I did things that were enjoyable. & 0.705 & -0.015 & 0.739 & 0.026 \\
\hline
\end{tabular}

Cronbach's alpha coefficient was calculated to evaluate the scale's internal consistency. The alpha for the complete scale in Brazil was $0.55(\mathrm{Cl}=0.52$ to 0.58$)$, the Activation and Avoidance subscales were 0.70 $(\mathrm{Cl}=0.69$ to 0.72$)$ and $0.58(\mathrm{Cl}=0.55$ to 0.61$)$, respectively. The exclusion of item 8 would increase the overall alpha to 0.62 . The removal of item 1 from the Activation subscale and the inclusion of this item in the Avoidance subscale slightly increases both alphas: $0.75(\mathrm{Cl}=0.73$ to 0.76$)$ for the Activation subscale and $0.60(\mathrm{Cl}=0.58$ to 0.63$)$ for the Avoidance subscale. 
In Peru, the complete scale presented an alpha of $0.66(\mathrm{Cl}=0.63$ tot 0.69$), 0.75(\mathrm{Cl}=0.73$ to 0.77$)$ for the Activation subscale, and $0.65(\mathrm{Cl}=0.62$ to 0.68$)$ for the Avoidance subscale.

KMO of 0.769 and 0.790 for Brazilian and Peruvian versions, respectively, and significance of 0.000 of the Bartlett's test of Sphericity for both confirms sampling adequacy.

\section{Discussion}

The objective of this study was to describe the adaptation of Brazilian and Peruvian versions of the Behavioral Activation for Depression Scale in its short version (BADS-SF) and to determine its psychometric properties. Our main results show CVI for both scales is valid (CVI $=0.91$ in Brazil and 0.86 in Peru), with sufficient test results for sampling adequacy and positive internal consistency as measured by the Cronbach's alpha. Internal consistency results improve with a different organization of the subscales. This result is related to the factor distribution of our versions of the scale - our data suggest a different item distribution among factors when compared with the original version.

At the time of submission of this article, some studies had evaluated the psychometric properties of the short version of this scale in different languages and cultures, including Spanish [25-29], but none for Brazilian or Peruvian populations.

The construct validity of the Brazilian and Peruvian versions of the BADS-SF was assessed using the Principal Component Analysis method (PCA), which resulted in a two-factor solution. This result echoes the findings of the English version of the BADS-SF, and the naming of both factors, Avoidance and Activation, is sustained. However, the factor load of items demonstrated a different distribution of the items among the factors, placing item 1 (There were certain things I needed to do that I didn't do) in the avoidance subscale, which also occurred in one of the studies in the original validation studies and other languages validations [14]. This different organization of items into factors also increases Cronbach's alpha in both studied versions.

Cronbach's Alpha for the BADS-SF was 0.55 in Brazil, not a high internal consistency index according to the literature [22]. In Peru, Cronbach's Alpha was 0.66 , within the range of reliability. However, very high measurements for the alpha do not necessarily represent a more consistent scale but may indicate redundancy in the construction of the items or an unnecessarily long scale, since the alpha value is affected according to the number of items on the scale [30]. The original validation study of the BADS-SF found $\nabla=0.82[14]$. Other studies have found different values, ranging from 0.46 to 0.89 , showing this measure might be controversial.

Hence, although the removal of item 8 (I engaged in activities that would distract me from feeling bad) could improve the overall alpha of the Brazilian scale, we decided to keep this item due to the size of the scale, lack of agreement in the literature of what would be a good alpha cut-off point, and because some items have a clinically relevant application and can be valuable in a clinical context to help follow up patient progress. 
The same rationale was applied to the communality value identified for item 3 (I engaged in many different activities) of the Brazilian version of the BADS-SF, as literature points to communalities cut-off values ranging from 0.4 to $0.5[20]$ and the item behaved as expected on the PCA.

In the present study and all cited studies on BADS-SF psychometric validity, Cronbach's Alpha was higher for the activation subscale than for the complete scale and lower for the avoidance subscale. Very often the avoidance subscale did not reach desirable reliability or was limitrophe, which complies with the original version authors' recommendations of using other tools if the objective is to measure avoidance.

Although Brazil and Peru have very distinct historical backgrounds, languages, and cultures, we found similar results in our psychometric analysis for both versions, indicating the adequacy of the scale adaptation. This study corroborates previous data showing the BADS-SF is a consistent measure to assess both activation and avoidance in research and clinical contexts in different cultures and settings $[14,25,27,29,31-33]$. It is of utmost relevance and importance to present current results of using this scale with people with depressive symptoms in two different countries in Latin America.

Cronbach's alpha results and factor analysis allowed us to conclude we have an internally consistent version of the scales in both versions, however, with factor organization different from the original version. This also happened in other adapted versions of the scale [27, 31].

\section{Limitations Of The Study}

Our findings face some limitations. Both adapted versions were not submitted to face validity assessment with research participants, which hindered us from knowing if further adaptations and corrections were needed.

The population sample in this study is composed of chronic patients (those with diabetes and/or hypertension) in treatment for this condition in public health services in both countries. In Brazil, the study concentrates on patients of the eastern region of Sao Paulo, known for its low-income rate.

It may not represent the entire population of those localities.

\section{Conclusion}

Our psychometric results are acceptable and show both Peruvian and Brazilian versions of BADS-SF have a coherent structure and internal consistency. Considering both sites presented the same pattern of item adherence we suggest the following distribution of items into subscales: items 2 to 5 and item 9 Activation subscale; item 1 and items 6 to 8 - Avoidance subscale.

This scale will allow clinicians to assess and follow-up on patients' activation and avoidance, as an evidence-based practice to treat depression in the general population. 
Further psychometric studies should focus on assessing item by item contribution to the scale and test possible distortion of the measurement using psychometric tests such as the Rasch model approach or Item response theory.

\section{List Of Abbreviations}

BA: Behavioral Activation

BADS-SF: Behavioral activation for depression Scale - Short Form

CVI: Content Validity Index

FHU: Family Health Institute

GBD: Global Burden of Diseases

LATIN-MH: Latin America Treatment and Innovation Network

LMICs: Low-middle Income Countries

MDD: Major Depressive Disorder

NIH: National Institutes of Health

PCA: Principal Component Analysis

PHC: Patient Health Care Center

PHQ-9: Patient Health Questionnaire - 9

RCT: Randomized Controlled Trial

SPSS: Statistical Package for the Social Sciences

YLDs: Years Lived with Disability

\section{Declarations}

\section{Ethics approval and consent to participate}

This study was carried out in accordance with all relevant regulations and guidelines for experimental research on humans. The study was approved by the ethics committee of the Faculty of Medicine of Sao Paulo University (FMUSP) board, under the registration code: 26392719.6.0000.0065. It is part of a matrix study - trial registration NCT028406662 (Sao Paulo), NCT03026426 (Lima). All the ethics boards involved are registered and licensed ethics in human research committees. 
Written informed consent for participation was taken from all the study participants, which included authorization for participation in both the matrix and present study. The objectives of the study were described and explained to all participants. Participants were informed about the confidentiality of the data and about their right to withdraw from the study at any time.

\section{Consent for publication}

Not applicable.

\section{Availability of data and materials}

The corresponding author agrees to make datasets used in this study available upon reasonable request.

\section{Competing interests}

All authors declare no competing interests.

\section{Funding}

The National Institute of Mental Health funded this research (1U19MH098780).

\section{Authors' contributions}

All authors read, critically revised, and approved the final version of this paper and participated in the matrix study planning, implementation, and data analysis. SA and HGC conceptualized the idea. SA wrote the first draft and synthesized the author's suggestions. HGC and IFALF were responsible for data analysis and interpretation. KD, HCSM, DVC, TIUR and IH have contributed to desk research and manuscript structuring and organization. PM and RA, as senior researchers, supervised and advised the development of this manuscript and the study as a whole.

\section{Acknowledgments}

This research is part of the matrix study "Effectiveness of a Mobile Technology Intervention for the Treatment of Depression (Latin-MH)". The psychometric properties measurement of both scales in Peruvian and Brazilian versions compose a doctorate dissertation from the Faculty of Medicine of Sao Paulo University. We thank the assistance and participation of both the cities of São Paulo and Lima and all staff from health services and universities involved in data collection and study implementation.

\section{References}

1. Claro HG, de Oliveira MAF, de Almeida MM, De Vargas D, Plaglione HB. Adaptação cultural de instrumentos de coleta de dados para mensuração em álcool e drogas. SMAD. Revista Eletrônica Saúde Mental Álcool e Drogas (Edição em Português). 2011;7:71. doi:10.11606/issn.18066976.v7i2p71-77. 
2. Borsa JC, Damasio BF, Bandeira DR. Cross-cultural adaptation and validation of psychological instruments: Some considerations. Paidéia (Ribeirão Preto): cadernos de psicologia e educação Vol 22, n 53,(set /dez 2012), p 423-432. 2012. https://www.lume.ufrgs.br/handle/10183/98929.

3. GBD 2017 Disease and Injury Incidence and Prevalence Collaborators. Global, regional, and national incidence, prevalence, and years lived with disability for 354 diseases and injuries for 195 countries and territories, 1990-2017: a systematic analysis for the Global Burden of Disease Study 2017. Lancet. 2018;392:1789-858.

4. Organization WH, Others. Mental health action plan 2013-2020. 2013. https://apps.who.int/iris/bitstream/handle/10665/89966/9789241506021_eng.pdf.

5. Hock RS, Or F, Kolappa K, Burkey MD, Surkan PJ, Eaton WW. A new resolution for global mental health. Lancet. 2012;379:1367-8.

6. Roca M, Del Amo AR-L, Riera-Serra P, Pérez-Ara MA, Castro A, Roman Juan J, et al. Suicidal risk and executive functions in major depressive disorder: a study protocol. BMC Psychiatry. 2019;19:253.

7. Suicide. https://www.who.int/news-room/fact-sheets/detail/suicide. Accessed 26 Nov 2020.

8. Organization WH, Others. Depression and other common mental disorders: global health estimates. World Health Organization; 2017. https://apps.who.int/iris/bitstream/handle/10665/254610/WHOMSD-MER-2017.2-eng.pdf.

9. Kohn R, Ali AA, Puac-Polanco V, Figueroa C, López-Soto V, Morgan K, et al. Mental health in the Americas: an overview of the treatment gap. Rev Panam Salud Publica. 2018;42:e165.

10. Hopko DR, Lejuez CW, Ruggiero KJ, Eifert GH. Contemporary behavioral activation treatments for depression: procedures, principles, and progress. Clin Psychol Rev. 2003;23:699-717.

11. Kanter JW, Puspitasari AJ, Santos MM, Nagy GA. Behavioural activation: history, evidence and promise. Br J Psychiatry. 2012;200:361-3.

12. Kanter JW, Santiago-Rivera AL, Santos MM, Nagy G, López M, Hurtado GD, et al. A randomized hybrid efficacy and effectiveness trial of behavioral activation for Latinos with depression. Behav Ther. 2015;46:177-92.

13. Kanter JW, Mulick PS, Busch AM, Berlin KS, Martell CR. The Behavioral Activation for Depression Scale (BADS): Psychometric Properties and Factor Structure. Journal of Psychopathology and Behavioral Assessment. 2007;29:191-202. doi:10.1007/s10862-006-9038-5.

14. Manos RC, Kanter JW, Luo W. The Behavioral Activation for Depression Scale-Short Form: Development and Validation. Behav Ther. 2011;42:726-39.

15. Rocha TIU, Aschar SC de AL, Hidalgo-Padilla L, Daley K, Claro HG, Martins Castro HC, et al. Recruitment, training and supervision of nurses and nurse assistants for a task-shifting depression intervention in two RCTs in Brazil and Peru. Hum Resour Health. 2021;19:16.

16. Beaton DE, Bombardier C, Guillemin F, Ferraz MB. Guidelines for the process of cross-cultural adaptation of self-report measures. Spine. 2000;25:3186-91. 
17. Sousa VD, Rojjanasrirat W. Translation, adaptation and validation of instruments or scales for use in cross-cultural health care research: a clear and user-friendly guideline. Journal of Evaluation in Clinical Practice. 2011;17:268-74. doi:10.1111/j.1365-2753.2010.01434.x.

18. Barraca J, Pérez-Alvarez M, Lozano Bleda JH. Avoidance and activation as keys to depression: adaptation of the Behavioral Activation for Depression Scale in a Spanish sample. Span J Psychol. 2011;14:998-1009.

19. Claro HG, de Oliveira MAF, Paglione HB, Pinho PH, Pereira MO, de Vargas D. Tradução e adaptação cultural do global appraisal of individual needs - initial. Revista da Escola de Enfermagem da USP. 2012;46:1148-55. doi:10.1590/s0080-62342012000500016.

20. Shokuhi ZB, Ranjbar F, Hakimi S, Bahri R, Ghaffarifar S. Psychometric properties of the Persian version of postpartum distress measure scale. BMC Psychiatry. 2020;20:84.

21. Guillemin F, Bombardier C, Beaton D. Cross-cultural adaptation of health-related quality of life measures: literature review and proposed guidelines. J Clin Epidemiol. 1993;46:1417-32.

22. Ursachi G, Horodnic IA, Zait A. How Reliable are Measurement Scales? External Factors with Indirect Influence on Reliability Estimators. Procedia Economics and Finance. 2015;20:679-86.

23. Parent MC. Handling Item-Level Missing Data. The Counseling Psychologist. 2013;41:568-600. doi:10.1177/0011000012445176.

24. Factor Analysis, Path Analysis, and Structural Equation Modeling. Principles of Research in Behavioral Science. 2012;:358-81. doi:10.4324/9780203085219-21.

25. Santos MM. Validation of the behavioral activation for depression scale - short form (BADS-SF) with Spanish-speaking Latinos. http://dc.uwm.edu/cgi/viewcontent.cgi?article=1158\&context=etd. Accessed 4 Feb 2021.

26. González-Roz A, Secades-Villa R, Muñiz J. Validity evidence of the Behavioral Activation for Depression Scale-Short Form among depressed smokers. Int J Clin Health Psychol. 2018;18:162-9.

27. Fuhr K, Hautzinger M, Krisch K, Berking M, Ebert DD. Validation of the Behavioral Activation for Depression Scale (BADS)-Psychometric properties of the long and short form. Compr Psychiatry. 2016;66:209-18.

28. Wagener A, Van der Linden M, Blairy S. Psychometric properties of the French translation of the Behavioral Activation for Depression Scale-Short Form (BADS-SF) in non-clinical adults. Compr Psychiatry. 2015;56:252-7.

29. Shudo Y, Yamamoto T. Assessing the relationship between quality of life and behavioral activation using the Japanese Behavioral Activation for Depression Scale-Short Form. PLOS ONE. 2017;12:e0185221. doi:10.1371/journal.pone.0185221.

30. Panayides P. Coefficient alpha: interpret with caution. Europe's Journal of Psychology. 2013;9:68796.

31. Wagener A, Van der Linden M, Blairy S. Behavioral Activation for Depression Scale-Short Form; French Version. PsycTESTS Dataset. 2016. doi:10.1037/t54508-000. 
32. Shudo Y, Yamamoto T, Sakai M. Longitudinal Predictions of Depression Symptoms Using the Activation and Avoidance Subscales of the Japanese Behavioral Activation for Depression ScaleShort Form. Psychological Reports. 2017;120:130-40. doi:10.1177/0033294116680794.

33. Petts RA, Foster CS, Douleh TN, Gaynor ST. Measuring activation in adolescent depression: Preliminary psychometric data on the Behavioral Activation for Depression Scale-Short Form. Behavior Analysis: Research and Practice. 2016;16:65-80. doi:10.1037/bar0000036.

\section{Figures}

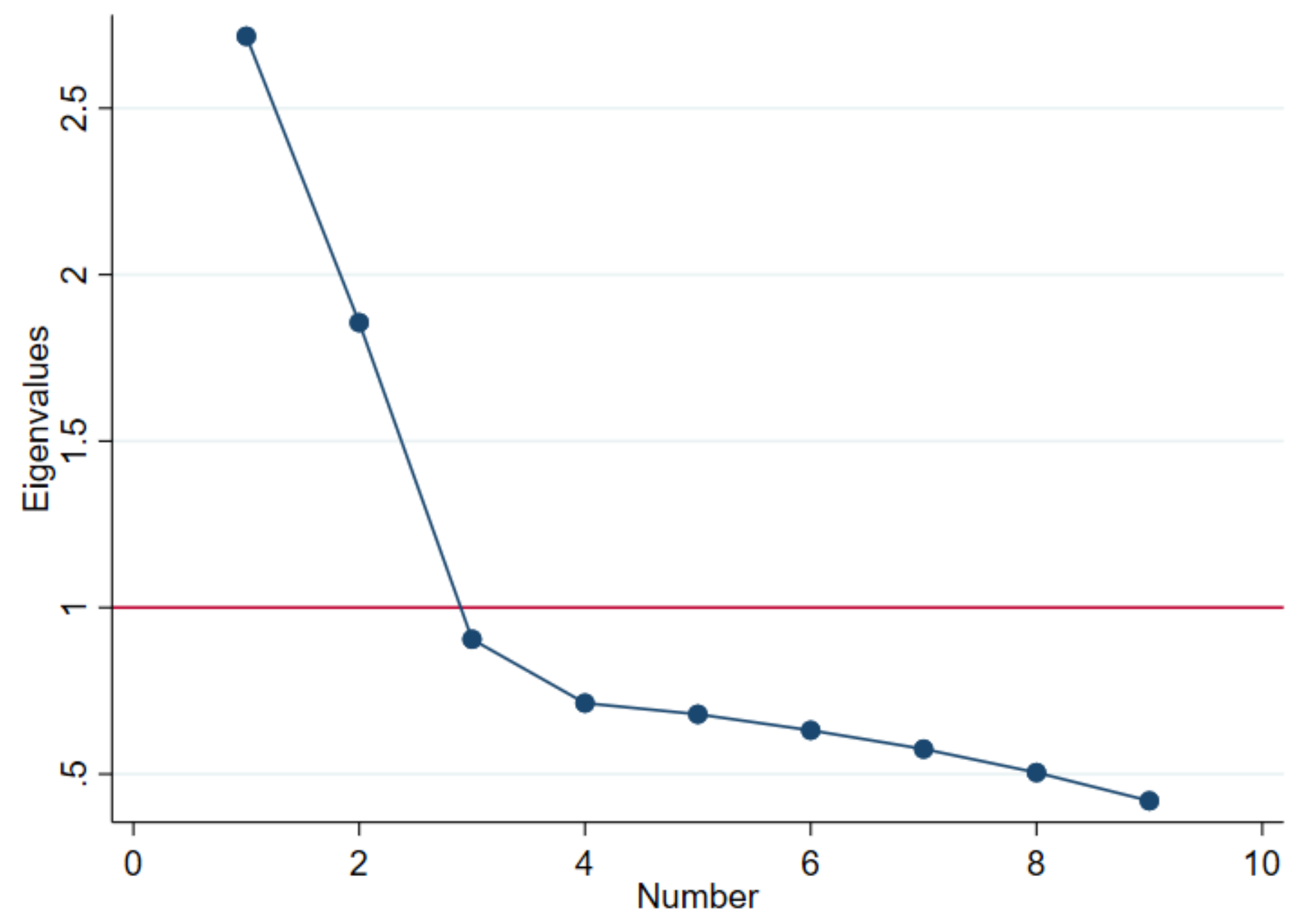

\section{Figure 1}

Factor load scree plot demonstrating extracted factors of the Brazilian version of the BADS-SF. 


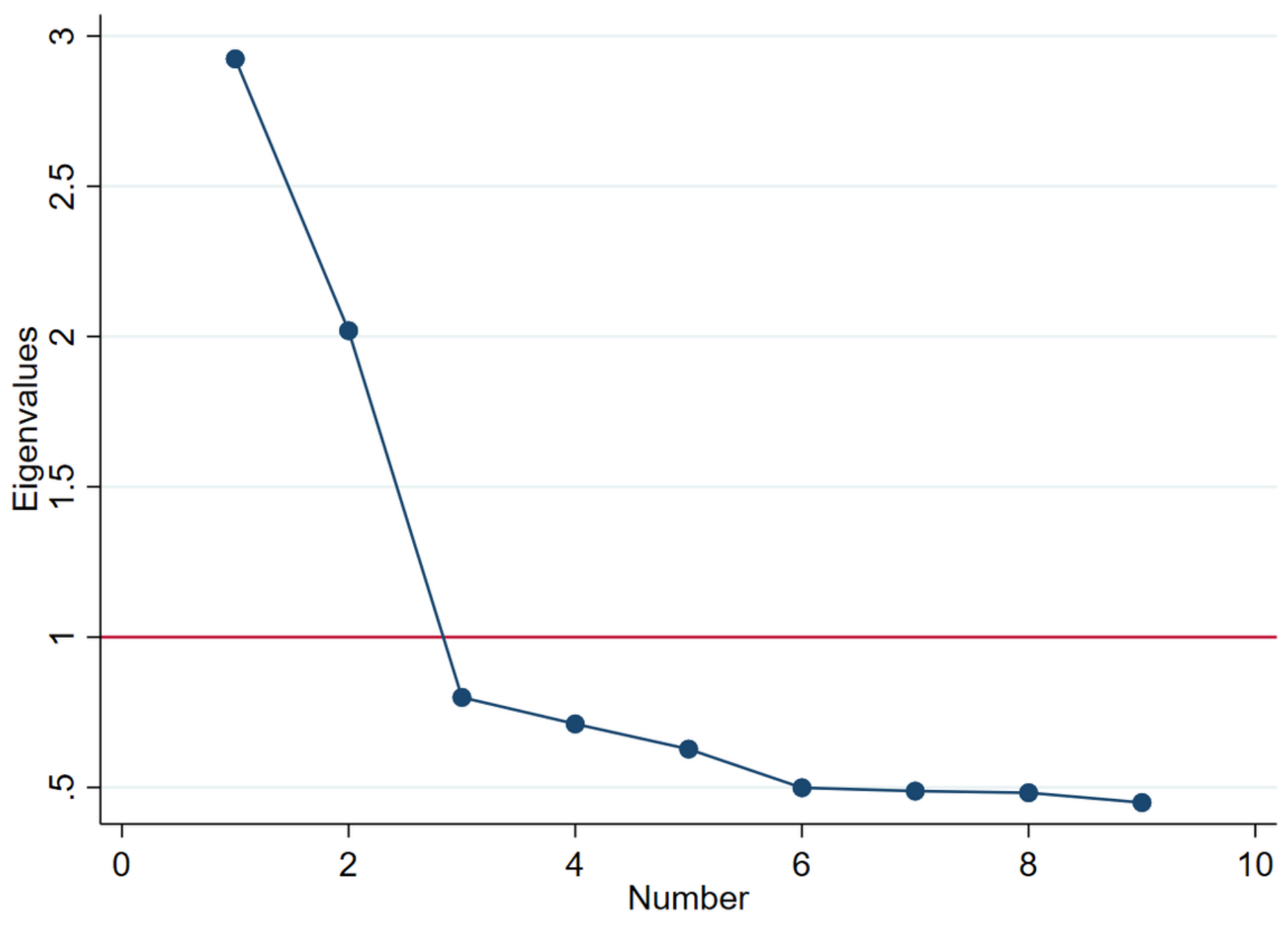

Figure 2

Factor load scree plot demonstrating extracted factors of the Peruvian version of the BADS-SF. 